\title{
Impactos da pandemia
}




\section{Medicamentos e tratamentos para a Covid-19 \\ LEONARDO L. G. FERREIRA I e ADRIANO D. ANDRICOPULO II}

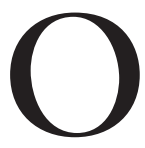

SARS-CoV-2 (coronavírus da síndrome respiratória aguda grave 2) se espalhou rapidamente pelo mundo, a partir de Wuhan-China, causando graves implicações socioeconômicas e de saúde pública. O panorama global, de janeiro a setembro de 2020, é devastador. Mais de 33 milhões de pessoas foram infectadas com o vírus, que é o causador da Covid-19, doença que causou a morte de cerca de 1 milhão de pessoas (WHO, 2020; Zhu et al., 2020). Somente no Brasil, no mesmo período, foram aproximadamente 4,8 milhões de casos confirmados da doença e 143 mil mortes, com mais de 4 milhões de recuperados. O Brasil ocupa a terceira colocação mundial em número de casos de Covid-19, ficando atrás dos Estados Unidos e da Índia, que registraram cerca de 7,1 e 6,1 milhões de casos, respectivamente, e a segunda colocação em número de mortes, superado apenas pelos Estados Unidos, que já ultrapassou a marca de 205 mil mortes (WHO, 2020).

Encontrados em diversas espécies de mamíferos e pássaros, os coronavírus são vírus de RNA fita simples de sentido positivo (ssRNA+), envolvidos por um envelope lipídico. Algumas espécies são conhecidas por causar doenças respiratórias, entéricas, hepáticas e neurológicas. As espécies 229E, OC43, NL63 e HKUl são os agentes etiológicos dos resfriados comuns, enquanto outros coronavírus como o Sars-CoV e o vírus da síndrome respiratória do Oriente Médio (Mers-CoV) podem ser fatais (Cui et al., 2019). O Sars-CoV causou surtos de síndrome respiratória aguda em Guangdong-China, entre 2002 e 2003, e o Mers-CoV foi responsável por casos de doença respiratória grave no Oriente Médio em 2012 (Zhong et al., 2003; Zaki et al., 2012). O Sars-CoV-2 produz uma síndrome respiratória que pode variar de um quadro inflamatório leve e autolimitado a pneumonia progressiva e grave. Os casos mais críticos evoluem para a falência de órgãos levando à morte (Cao et al., 2020).

A pandemia impôs grandes desafios a todas as nações e povos do nosso planeta, em especial à comunidade científica internacional, que respondeu de forma rápida e eficiente em várias esferas prioritárias, como no desenvolvimento de novos tratamentos, vacinas e diagnósticos, entre outros, apoiada em conhecimento e inovação (Ferreira; Andricopulo, 2020). Este artigo delineia o cenário atual do desenvolvimento de candidatos a novos medicamentos (moléculas pequenas ou biológicos) para a Covid-19. 


\section{Processo de descoberta e desenvolvimento de fármacos}

O componente principal de uma formulação farmacêutica empregada como medicamento é denominado fármaco ou princípio ativo. É geralmente uma molécula pequena, de origem natural ou sintética, que possui estrutura química definida e é capaz de ajustar ou modificar funções fisiológicas, sendo usado para tratar, curar ou prevenir doenças e disfunções em humanos (Wermuth et al., 1998). Até chegar à aprovação, última etapa antes da comercialização, o fármaco passa por um longo e complexo processo de Pesquisa e Desenvolvimento (P\&D), que é caracterizado por elevados investimentos e riscos (DiMasi, 2020).

O processo de P\&D de moléculas pequenas (peso molecular $<1.000 \mathrm{Da}$ ) envolve duas fases fundamentais, chamadas de fases de descoberta (ou pré-clínica) e desenvolvimento (ou clínica) (Figura 1). O objetivo é aprimorar e potencializar a melhor combinação de características farmacodinâmicas (potência, afinidade e seletividade), farmacocinéticas (ADME: administração, distribuição, metabolismo e excreção) e toxicológicas para assegurar duas propriedades indispensáveis para um novo medicamento: segurança e eficácia (Dowden; Munro, 2019). A fase pré-clínica, que pode levar de dois a seis anos, envolve diversas etapas, incluindo: identificação e validação de alvos moleculares (proteínas-alvo); realização de triagens biológicas e computacionais; planejamento, síntese e avaliação in vitro de novas moléculas bioativas; otimização de propriedades como potência, seletividade e ADME; até a investigação in vivo dos compostos mais promissores em modelos experimentais em animais. Essa fase se encerra com a descoberta de um candidato a novo fármaco, denominado nova entidade química (NCE, New Chemical Entity). Após a aprovação da NCE pela agência reguladora tem início a fase clínica, que é composta pelas fases 1,2 e 3 . Na fase clínica 1 são avaliados voluntários saudáveis em relação à segurança e as dosagens do candidato a fármaco. Na fase clínica 2, a NCE é administrada em pacientes para a avaliação da segurança e eficácia. Por sua vez, a fase clínica 3 é responsável por ampliar os testes de avaliação de segurança e eficácia para um grande número de pacientes, com ampla cobertura mundial, bem como estabelecer os protocolos de formulação e produção industrial do medicamento. Por fim, as agências reguladoras revisam todos os dados das triagens clínicas para a aprovação do registro do novo medicamento. No Brasil, a Agência Nacional de Vigilância Sanitária (Anvisa) é a agência reguladora de medicamentos, e nos Estados Unidos, a equivalente é a Administração de Alimentos e Medicamentos (FDA, Food and Drug Administration). A fase clínica 4 tem início após a comercialização do medicamento e são monitoradas as reações adversas inesperadas a longo prazo, bem como o impacto do novo produto na promoção da saúde. 


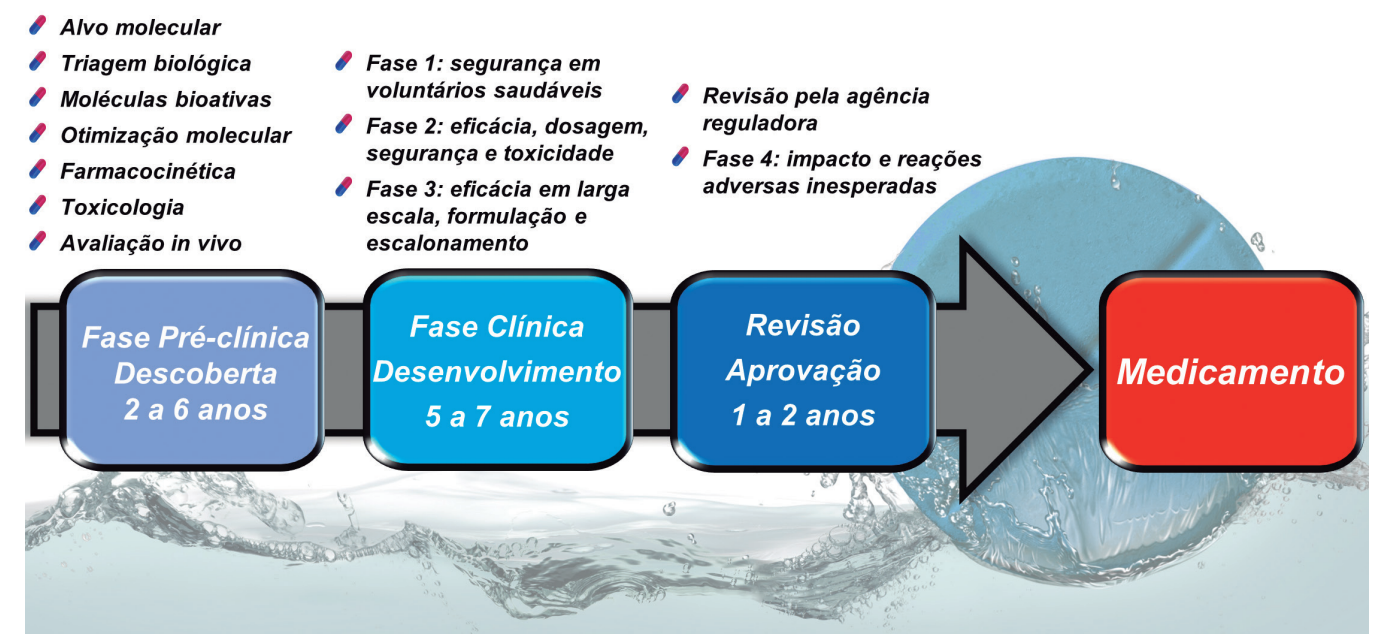

Fonte: Elaboração própria.

Figura 1 - Processo de P\&D de fármacos: fases pré-clínica e clínica, e o processo de revisão e aprovação do novo medicamento.

Por outro lado, os medicamentos biológicos são produzidos a partir de organismos vivos, incluindo moléculas produzidas por células humanas, animais ou microrganismos. Essas moléculas são obtidas por meio de técnicas de biotecnologia, como a tecnologia de DNA recombinante, ou ainda por síntese química (Zelikin et al., 2016). De forma geral, os medicamentos biológicos são macromoléculas que apresentam problemas de estabilidade, sensibilidade à degradação enzimática e baixa absorção gastrointestinal e são geralmente administrados por via intramuscular, intravenosa ou subcutânea. Além disso, moléculas de origem biológica podem ser imunogênicas e causar reações de hipersensibilidade que afetam a sua eficácia e segurança (Kishimoto et al., 2016). Insulina, citocinas, hormônios de crescimento, heparinas, interferons e anticorpos monoclonais são exemplos de medicamentos biológicos empregados na terapia de diversas doenças humanas. Vale destacar que o processo de P\&D de medicamentos biológicos é similar ao de moléculas pequenas, incluindo as fases de descoberta (pré-clínica) e desenvolvimento (fases clínicas: 1, 2 e 3), bem como as etapas de revisão e aprovação do registro pelas agências reguladoras.

\section{Reposicionamento de fármacos}

Para atender às demandas urgentes de uma pandemia, como a de Covid-19, os cientistas se mobilizaram na busca por novos tratamentos e o reposicionamento de fármacos surgiu naturalmente como a alternativa mais segura e viável. Essa estratégia busca identificar novas indicações para medicamentos aprovados ou candidatos em fases clínicas avançadas por meio de triagens fenotípicas, seguidas de ensaios clínicos de fases 2 e 3 (Pushpakom et al., 2019). Em comparação ao processo tradicional de P\&D, o reposicionamento de fármacos possui algumas vantagens. As principais são o tempo e o custo de desenvol- 
vimento bem menores, pois os testes de segurança (pré-clínica e clínica) e os protocolos de formulação e produção em larga escala já foram estabelecidos (Ferreira; Andricopulo, 2016).

Ao contrário do que muitos pensam, o reposicionamento de fármacos não é uma estratégia nova e com o seu uso alguns medicamentos chegaram ao mercado com aplicações inovadoras. São os casos da zidovudina (AZT, Figura 2), desenvolvida originalmente como agente anticâncer, que em 1987 foi aprovada como o primeiro antiviral para o tratamento da síndrome da imunodeficiência adquirida (Aids, Acquired Immunodeficiency Syndrome) (Tu et al., 2010); e da sildenafila (Viagra), originalmente desenvolvida para tratar doenças cardíacas, que foi aprovada em 1998 como o primeiro tratamento eficaz por via oral para a disfunção erétil (Ghofrani et al., 2006). Por outro lado, o reposicionamento de fármacos possui algumas limitações associadas à sua natureza de "tentativa e erro", sobretudo, para doenças que envolvem novas vias bioquímicas e alvos moleculares, muitas vezes não cobertos pelo espaço químico ocupado pelos medicamentos aprovados. Esse é o caso das triagens fenotípicas para a Covid-19, que se baseiam em testes nos quais são empregadas células humanas infectadas com o Sars-CoV-2 na presença de medicamentos e de outros candidatos a antivirais, na expectativa de que algum composto possa bloquear o vírus.
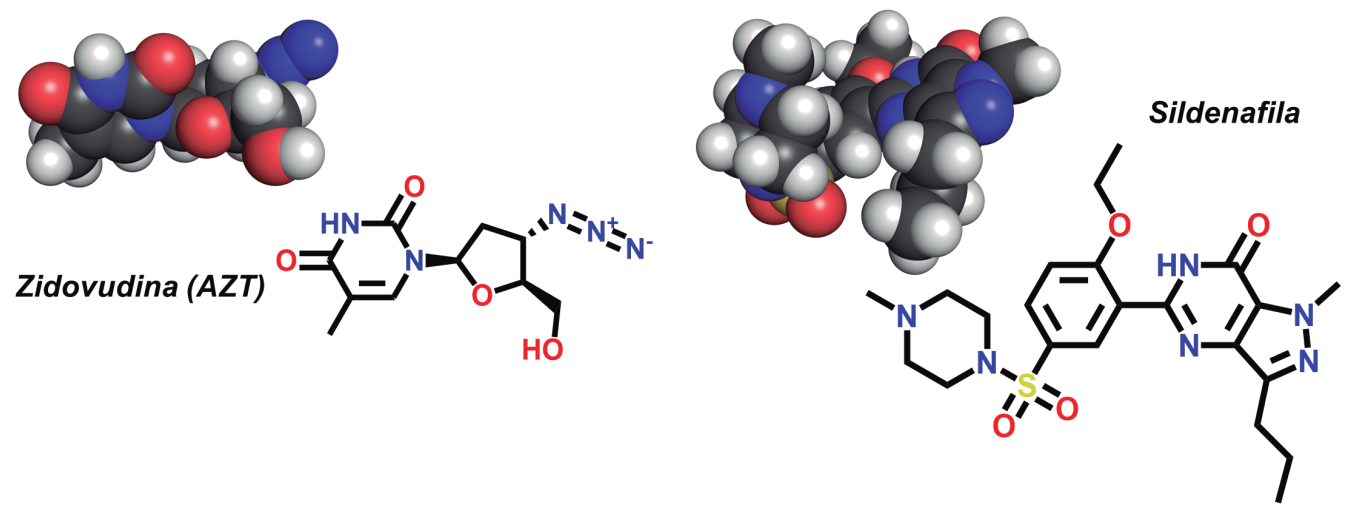

Fonte: Elaboração própria.

Figura 2 - Exemplos de reposicionamento de fármacos: AZT para a Aids e sildenafila para a disfunção erétil.

\section{Avaliação clínica de candidatos para a Covid-19}

A principal base de dados de registros de estudos clínicos, a ClinicalTrials. gov, mantida pela Biblioteca Nacional de Medicina nos Institutos Nacionais da Saúde (NIH, National Institutes of Health) dos Estados Unidos, possui aproximadamente 2.000 estudos clínicos registrados (até o final de setembro de 2020) para a Covid-19, considerando-se somente moléculas pequenas e biológicos. Outras bases de dados importantes, como a EU Clinical Trials Register, a ISRCTN e a Chinese Clinical Trial Registry (ChiCTR), também possuem diversos 
registros, totalizando em torno de 2.500 estudos clínicos, com cerca de 200 medicamentos, sem contar fitoterápicos e extratos diversos. As principais classes terapêuticas investigadas são antivirais, anticâncer, anti-hipertensivos, imunossupressores, antiparasitários e anti-inflamatórios, entre outras.

A grande demanda de testes clínicos e a necessidade de avaliar mais profundamente alguns candidatos induziram à organização de redes mundiais. Uma dessas iniciativas, a Recovery (Randomised Evaluation of Covid-19 Therapy ou Avaliação Randomizada da Terapia contra a Covid-19) foi estabelecida para investigar a eficácia de diferentes protocolos em pacientes hospitalizados com Covid-19 (Normand, 2020). Liderada pela Universidade de Oxford, são considerados atualmente os tratamentos com dexametasona, azitromicina, plasma convalescente, tocilizumabe e REGN-COV2. Os dados desses estudos são revisados regularmente para que qualquer tratamento eficaz possa ser identificado rapidamente e disponibilizado a todos os pacientes. O principal resultado desse estudo até o momento foi com a dexametasona (Figura 3), um corticoide com propriedades anti-inflamatórias e imunossupressoras, usado desde a década de 1960, que reduziu a taxa de mortalidade em pacientes graves recebendo ventilação mecânica invasiva ou oxigênio (Recovery Collaborative Group et al., 2020). Por outro lado, estudos no âmbito da Recovery descartaram definitivamente a hidroxicloroquina e lopinavir-ritonavir por não apresentarem nenhum benefício clínico em pacientes hospitalizados com Covid-19, a partir das evidências preliminares em estudos pré-clínicos realizados em laboratório. Outra iniciativa internacional, a Solidarity, liderada pela Organização Mundial da Saúde (OMS) para avaliar a eficácia de tratamentos para a Covid-19, considera presentemente os tratamentos com remdesivir (Figura 3), e lopinavir-ritonavir com interferon beta- la (Kupferschmidt; Cohen, 2020). Hidroxicloroquina e lopinavir-ritonavir também já foram descartadas como aconteceu na Recovery.
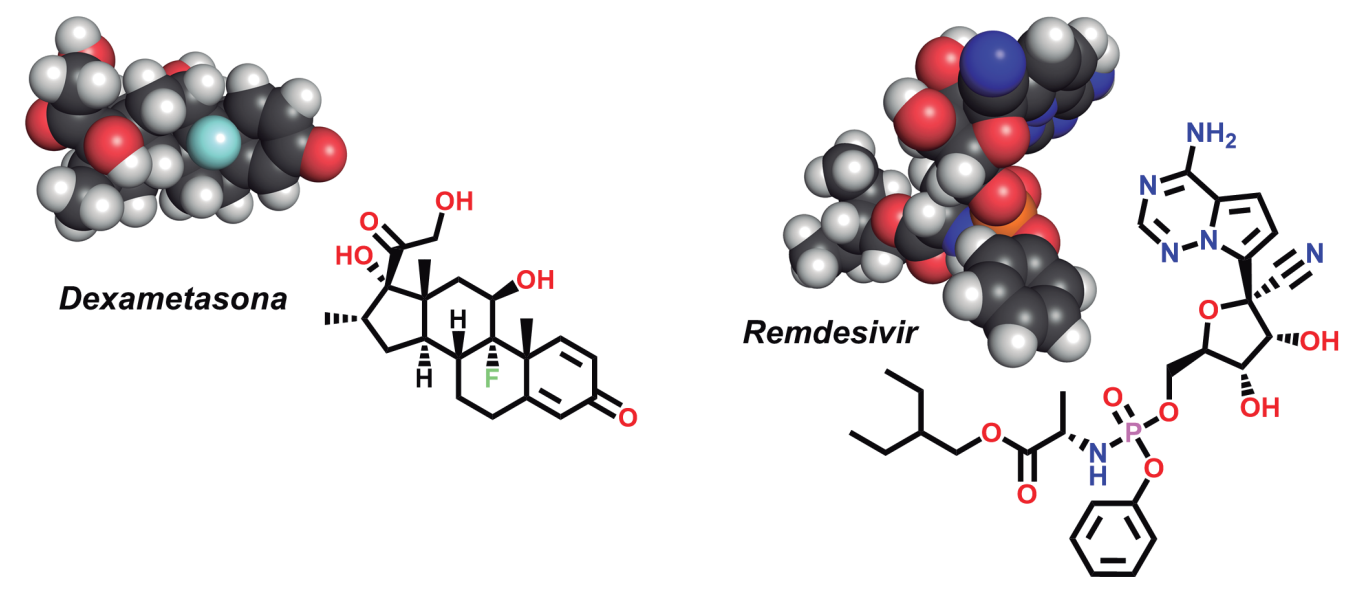

Fonte: Elaboração própria.

Figura 3 - Candidatos com resultados positivos nas iniciativas Recovery e Solidarity para a Covid-19. 


\section{Moléculas pequenas}

Entre os inúmeros candidatos clínicos em avaliação, o antiviral remdesivir, considerado originalmente em 2016 para o tratamento da infeção pelo vírus Ebola, apresentou resultados promissores e recebeu no início de maio deste ano aprovação do Food and Drug Administration (FDA) para uso emergencial em pacientes graves com Covid-19, que foi posteriormente expandida no final de agosto para o tratamento de pacientes com quadro moderado da doença. A atividade do remdesivir contra o Sars- $\mathrm{CoV}$ foi descrita inicialmente em 2017 (Sheahan et al., 2017). O remdesivir é o que chamamos de pró-fármaco, ou seja, uma forma inativa que deve ser metabolizada dentro da célula liberando a sua forma ativa, uma substância química modificada (GS-441524), que por sua vez é fosforilada em remdesivir-trifosfato (remdesivir-TP), para incorporação ao RNA inibindo a ação da RNA polimerase dependente de RNA (RdRp) viral (Figura 4). Como resultado, ocorre o bloqueio da transcrição de RNA do Sars-CoV-2 e a diminuição da produção de RNA viral.
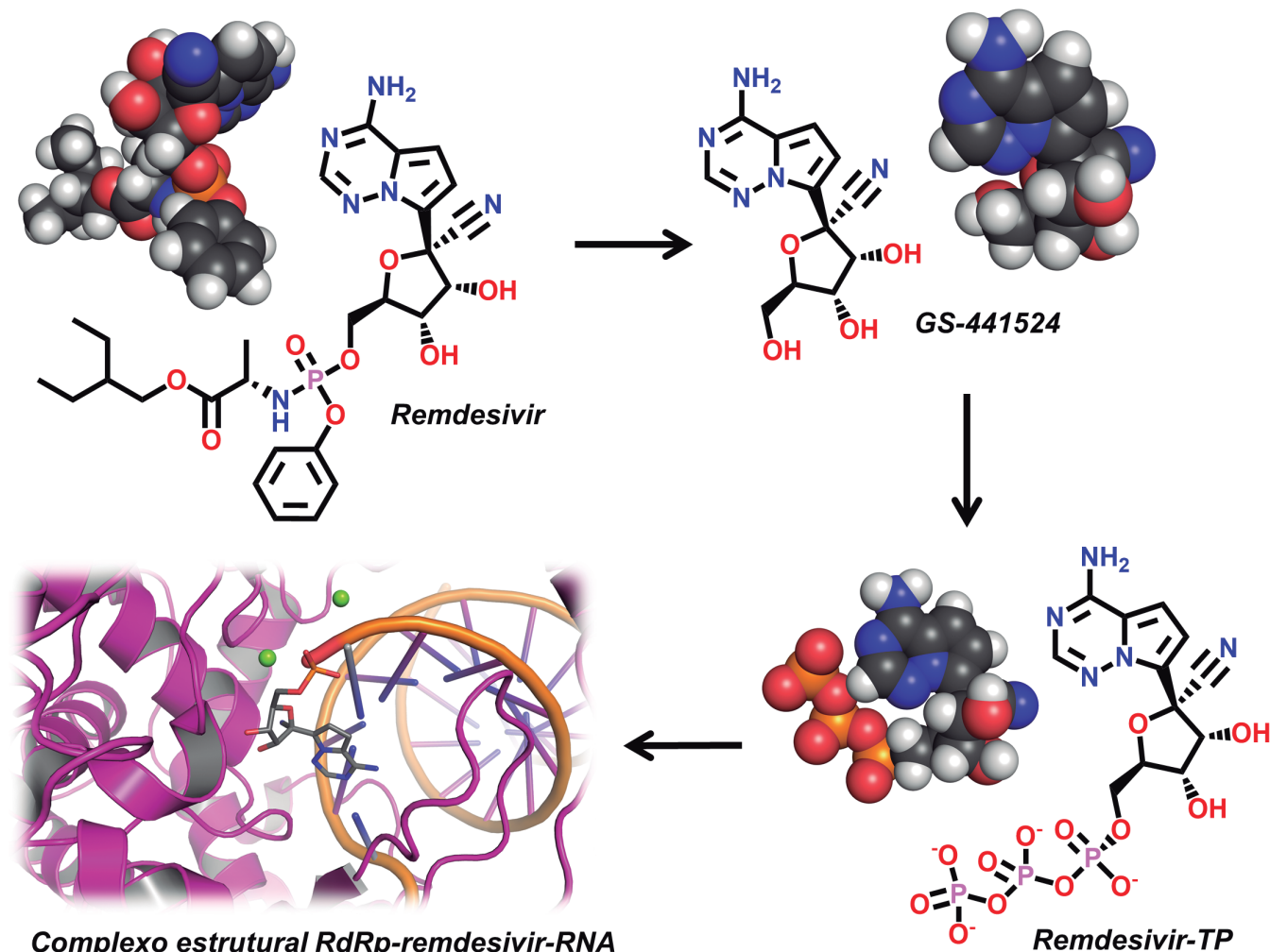

\section{Complexo estrutural RdRp-remdesivir-RNA}

Fonte: Elaboração própria.

Figura 4 - Mecanismo molecular de ação do remdesivir contra o Sars-CoV-2.

Os antivirais ritonavir e lopinavir (Figura 5) são inibidores da protease do vírus da imunodeficiência humana (HIV, Human Immunodeficiency Virus) desenvolvidos em 1996 e 2000, respectivamente, para o tratamento da Aids 
(Flexner, 1998). Em 2004, foi demonstrado que a combinação lopinavir-ritonavir e ribavirina (um inibidor da RNA polimerase viral usado no tratamento da hepatite C) reduziu a taxa de mortalidade e a necessidade de suporte respiratório em pacientes infectados com Sars-CoV; e em 2015, o lopinavir-ritonavir reduziu a carga viral e melhorou as condições pulmonares em animais infectados com Mers-CoV (Hung et al., 2020). Apesar desses resultados promissores, a terapia com lopinavir-ritonavir não apresentou nenhum benefício para pacientes hospitalizados com Covid-19 (Cao et al., 2020), justificando a interrupção de diversos testes clínicos, incluindo os das iniciativas Recovery e Solidarity, como mencionado anteriormente.

Tema de discussão em todo o mundo, a cloroquina e a hidroxicloroquina (Figura 5 ) são um capítulo à parte. O tratamento da Covid-19 com esses medicamentos já foi defendido por alguns médicos, cientistas e até chefes de Estado, mesmo sem nenhuma comprovação de sua eficácia em humanos. A cloroquina é um antimalárico sintético desenvolvido na década de 1930 (Packard, 2014). A hidroxicloroquina, um análogo hidroxilado da cloroquina, igualmente pertencente à classe das 4-aminoquinolinas, foi sintetizada em 1946 e possui como principal vantagem em relação a seu análogo mais simples uma menor toxicidade (Liu et al., 2020). A hidroxicloroquina é também usada no tratamento de doenças como lúpus eritematoso sistêmico e artrite reumatoide. Apesar de todas as controvérsias ao longo dos últimos meses, vários estudos indicaram que não há evidências científicas e benefícios clínicos para o uso da cloroquina e hidroxicloroquina em pacientes com manifestações das formas leve, moderada ou grave de Covid-19 (Maisonnasse et al., 2020; Funnell et al., 2020). Em razão dos resultados negativos, as iniciativas Recovery e Solidarity descartaram a hidroxicloroquina de seus portfólios de investigações clínicas.

A procura por soluções simples e sem comprovação científica parece não ter limites. Sem eficácia confirmada, um "kit covid-19" contendo azitromicina, ivermectina e cloroquina ou hidroxicloroquina, tem sido distribuído em alguns estados para a prevenção ou tratamento de pessoas com sintomas iniciais da doença. O uso do antibiótico azitromicina (Figura 6) com hidroxicloroquina é feito sem comprovação, desconsiderando estudos que demostraram que não têm eficácia (Rosenberg et al. 2020). O antiparasitário ivermectina, bem como a nitazoxanida (Figura 6), é mais um exemplo de uso sem comprovação de eficácia. Esses antiparasitários já foram alvos de estudos clínicos para outras doenças virais, mas não tiveram sucesso. A única vantagem desses medicamentos parece ser a ausência de efeitos colaterais graves, mas sem necessidade e supervisão médica, o seu uso deve ser descartado. 

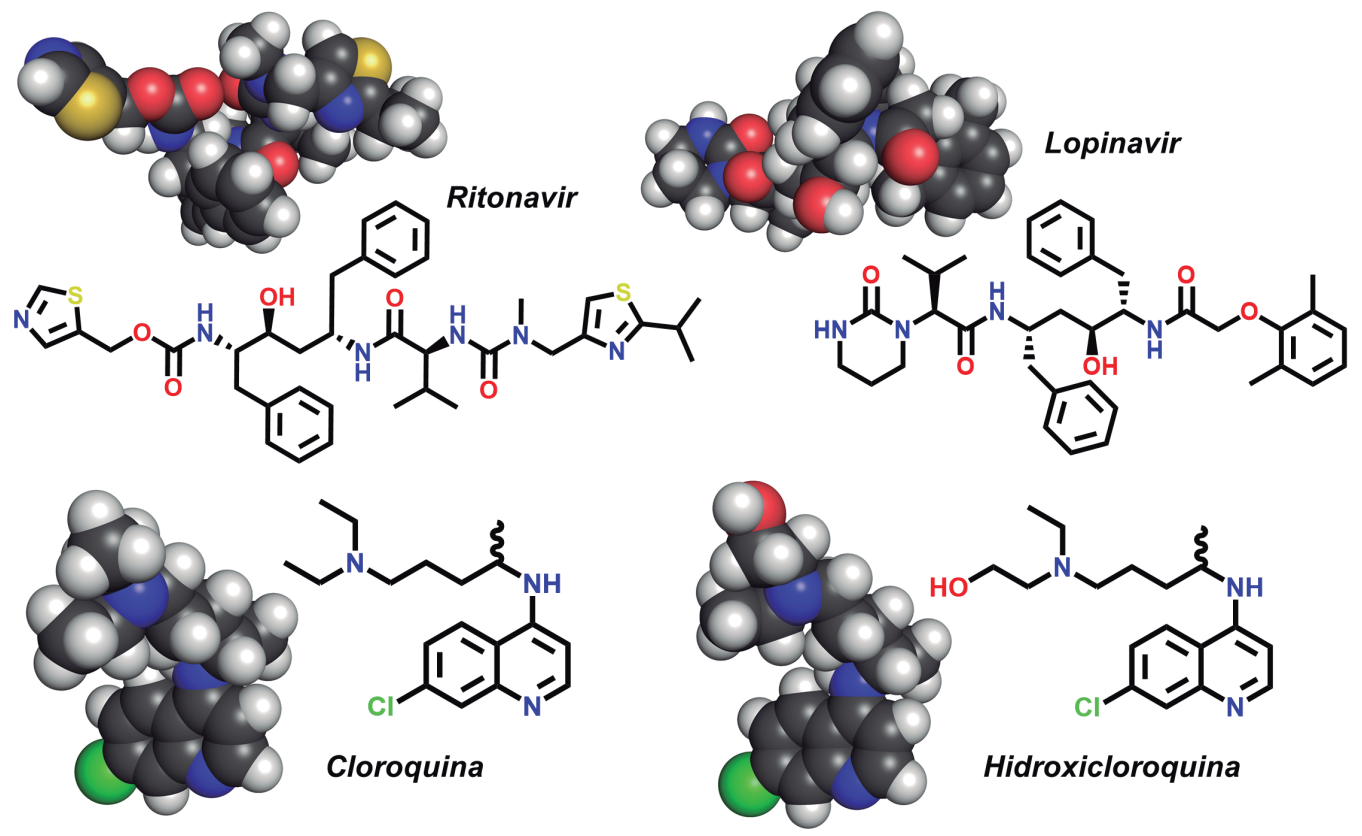

Fonte: Elaboração própria.

Figura 5 - Estruturas químicas dos antivirais ritonavir e lopinavir e dos antimaláricos cloroquina e hidroxicloroquina.
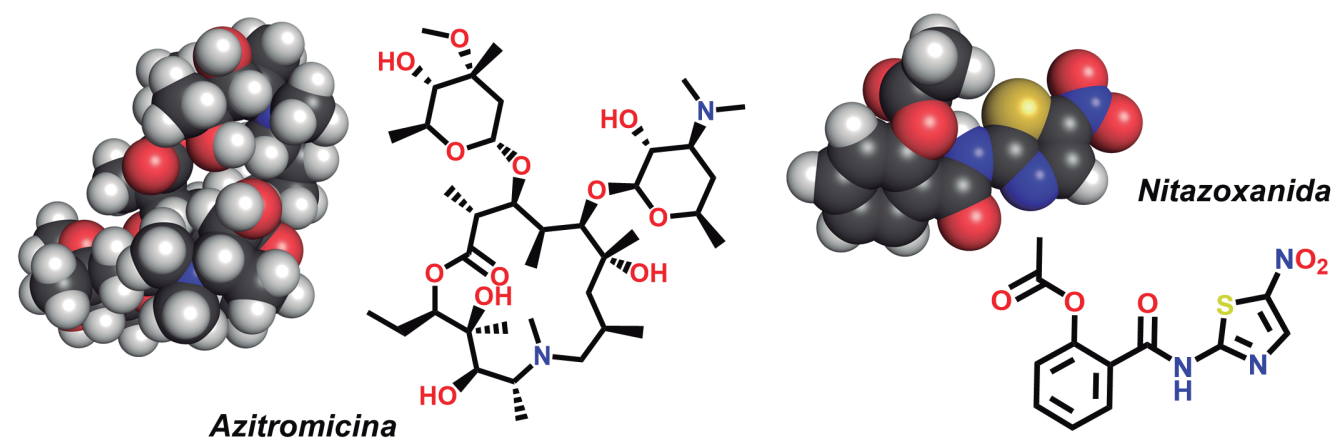

Azitromicina
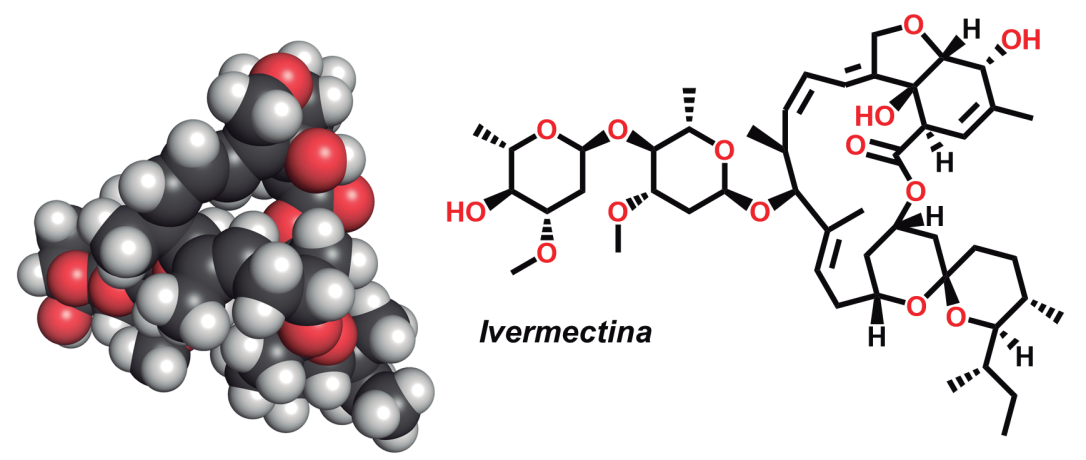

Fonte: Elaboração própria.

Figura 6 - Estruturas químicas do antibiótico azitromicina e dos antiparasitários ivermectina e nitazoxanida. 
A maioria dos pacientes (> 80-85\%) com Covid-19 se recupera sem a ajuda de nenhum tipo de tratamento, mas com frequência essa alta taxa de recuperação tem sido atribuída incorretamente ao uso de medicamentos sem comprovação. Por outro lado, um dos grandes problemas da disseminação de informações equivocadas sobre tratamentos sem comprovação científica é o aumento desenfreado da procura por alguns medicamentos. Além de colocar em risco a disponibilidade dos remédios para quem realmente precisa para tratar outras doenças, as pessoas acreditam estarem seguras e acabam flexibilizando as medidas efetivamente preventivas, como higienizar as mãos com água e sabão e álcool em gel, usar máscaras e adotar o distanciamento social.

O favipiravir (Figura 7), originalmente desenvolvido para o tratamento da gripe causada pelos vírus influenza A e B (Harrison, 2020), é outro pró-fármaco com modo de ação similar ao remdesivir. O seu metabólito ativo, favipiravirribofuranosil-5 -trifosfato (favipiravir-RTP), se liga e inibe a ação da RdRp, impedindo a replicação do genoma viral. No entanto, estudos comparativos com outros antivirais não demonstraram até o momento benefícios expressivos do favipiravir em relação aos protocolos padrões de tratamento (The Lancet Infectious Diseases, 2020). O candidato MK-4482 (anteriormente conhecido como EIDD-2801) (Figura 7) é mais um antiviral com mecanismo de ação semelhante ao remdesivir e que produziu resultados promissores em estudos de laboratório. Ensaios clínicos de fases 1 e 2 estão em andamento e os de fase 3 já estão previstos.

A oleandrina (Figura 7), composto altamente tóxico produzido pela planta oleandro (Nerium oleander), tem sido investigada em células infectadas com Sars-CoV-2, mas ainda não há evidências clínicas que indiquem a sua segurança e eficácia para o tratamento da Covid-19. Entre algumas outras opções atualmente consideradas, destaca-se a investigação de um coquetel de medicamentos em pacientes com a forma grave da doença. A proposta se baseia nos efeitos anti-inflamatórios do apremilast, em combinação com a redução de líquido nos pulmões do icatibanto, e com o bloqueio do sistema imunológico do cenicriviroc (Figura 7). Esses medicamentos serão também testados em combinação com o remdesivir e a dexametasona. 


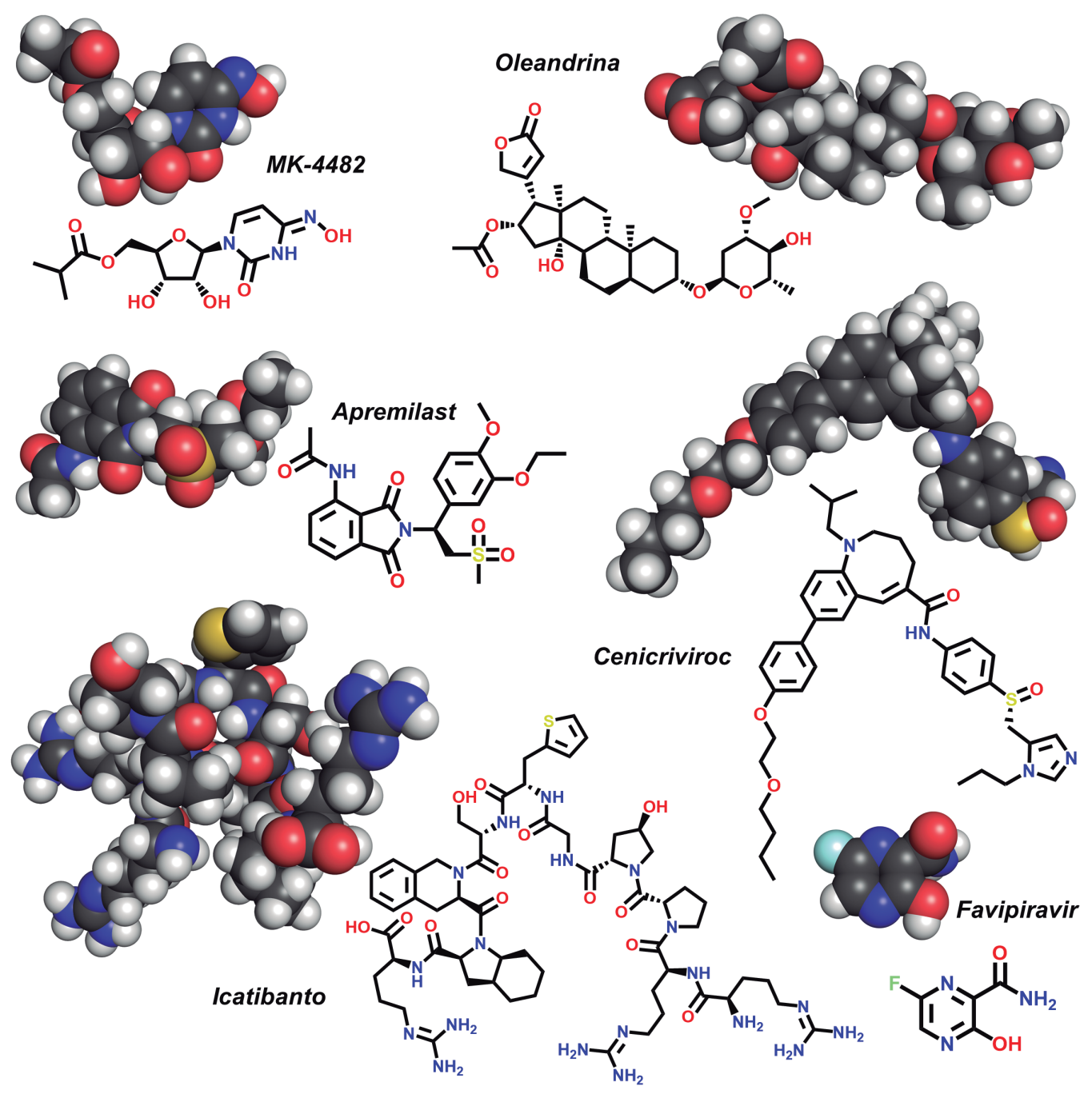

Fonte: Elaboração própria.

Figura 7 - Estruturas químicas do MK-4482, oleandrina, apremilast, cenicriviroc, icatibanto e favipiravir.

\section{Medicamentos biológicos}

Mudando o foco para os medicamentos biológicos, os anticorpos monoclonais são os mais explorados em ensaios clínicos para a Covid-19 (Cohen, 2020; Florindo et al., 2020). O tocilizumabe, um anticorpo monoclonal humano recombinante, tem sido muito estudado com a finalidade de reduzir a intensa resposta inflamatória ao vírus em pacientes graves, conhecida como tempestade de citocinas (De Rossi et al., 2020). As citocinas são proteínas que regulam a resposta imunológica, e a tempestade de citocinas é exatamente uma resposta imunológica excessiva, que progride rapidamente causando muitos danos ao organismo, com alta mortalidade. A interleucina-6 (IL-6) é uma citocina com papel central nos sérios danos pulmonares em pacientes graves. $\mathrm{O}$ tocilizumabe se liga ao receptor 
de IL-6 (IL6R) e inibe a transdução de sinal, diminuindo o processo inflamatório. Apesar de promissores indícios em relação à diminuição do tempo de recuperação de pacientes hospitalizados (Biran et al., 2020; Kewan et al., 2020), resultados decepcionantes da triagem clínica de fase 3 denominada Covacta foram anunciados. $\mathrm{O}$ tocilizumabe não reduziu a taxa de mortalidade em comparação com o placebo, levantando questionamentos sobre a eficácia do bloqueio da IL-6 em pacientes com pneumonia grave causada pela Covid-19 (Furlow, 2020). Resultados similares foram obtidos para o sarilumabe, outro anticorpo monoclonal humano modulador da IL-6, que teve seus estudos clínicos de fases 2 e 3 interrompidos.

Por outro lado, o anticorpo monoclonal IgGl LY-CoV555 apresentou bons resultados em estudos de fases 1 e 2 em pacientes com sintomas leves ou moderados, com diagnóstico recente de Covid-19. Atualmente em fase clínica 3 , esse anticorpo específico contra o Sars-CoV-2 foi planejado para interagir com a proteína Spike $(S)$ e impedir a adesão do vírus à membrana plasmática, bloqueando a sua entrada nas células. O LY-CoV555 será testado também em combinação com um segundo anticorpo, o LY-CoV016, que se liga a uma porção diferente da proteína $S$ do coronavírus. Outra inovação é o REGN-COV2, um coquetel de anticorpos antivirais que está sendo estudado em triagens clínicas de fases 2 e 3, inclusive na iniciativa Recovery, por seu potencial para tratar pacientes com Covid-19 e para prevenir a infecção por Sars-CoV-2. A segurança do REGN-COV2 também está sendo avaliada em um estudo de fase 1 em voluntários saudáveis (Hansen et al., 2020; Baum et al., 2020). Embora os anticorpos possam representar uma importante opção terapêutica de curto/médio prazo, a sua produção em larga escala e os altos custos de comercialização são grandes desafios em relação à sua acessibilidade e disponibilidade global.

Os interferons são glicoproteínas que estimulam o sistema imunológico a combater invasores externos, incluindo o Sars-CoV-2. Estudos sugerem que o aumento de interferons no organismo humano, especialmente no início da infecção, pode diminuir os efeitos da Covid-19 e os danos à saúde, como observado em tratamentos para outras doenças, como como a hepatite $\mathrm{C}$ e a esclerose múltipla. Estudos preliminares produziram resultados interessantes, que devem ser confirmados para estabelecer o real potencial da terapia e os possíveis efeitos colaterais em humanos.

O uso de plasma convalescente é outra abordagem terapêutica que está sendo testada em pacientes com Covid-19. Há mais de um século, o plasma convalescente de doadores recuperados de infecções tem sido transfundido em outros pacientes que apresentam a mesma infecção. Exemplos incluem Ebola, Mers e gripe HINl (Chen et al., 2020). Em meio a pandemia, a expectativa é que os anticorpos produzidos por doadores curados da doença possam auxiliar o sistema imunológico dos indivíduos receptores a neutralizar o vírus. No entanto, os estudos realizados foram feitos com pequenos grupos de pacientes, geralmente não randomizados e sem grupo controle (Ledford, 2020), não apresentando 
resultados conclusivos. Outra dificuldade é a grande variação que existe na concentração de anticorpos entre diferentes doadores. Estudos clínicos conduzidos na iniciativa Recovery estão em andamento e ainda não é possível avaliar a segurança e eficácia do uso de plasma convalescente no tratamento da Covid-19.

A enzima conversora de angiotensina 2 (ACE2, Angiotensin-Converting Enzyme 2), que se liga à proteína $S$ da superfície viral, foi identificada como receptor essencial para a infecção pelo Sars-CoV-2, que também envolve a serino-protease transmembrana 2 (TMPRSS2, Transmembrane Serine Protease 2) (Monteil et al., 2020). Proteínas ACE2 recombinantes mostraram resultados promissores em experimentos com células, mas ainda precisam demonstrar a sua ação em humanos. Além disso, o mecanismo molecular de ação sugere que a inibição dessas interações pode ser um tratamento útil. Dessa maneira, a entrada do vírus nas células poderia ser bloqueada por anticorpos neutralizantes da proteína $S$ e por inibidores da TMPRSS2.

Por fim, a heparina e outros anticoagulantes estão sendo avaliados em triagens clínicas de fases 2 e 3 para definir os possíveis benefícios e riscos na prevenção de infecções ou tratamento de pacientes hospitalizados com Covid-19 (NIH, 2020; Tandon et al., 2020).

\section{Fármacos específicos para a Covid-19}

O futuro próximo de P\&D de fármacos para a Covid-19 passa essencialmente por novos compostos baseados no mecanismo de ação contra proteínas específicas do Sars-CoV-2. Nesse contexto, o controle químico-biológico das interações intermoleculares entre alvos e moléculas pequenas é de grande valor. O planejamento de fármacos baseado na estrutura do receptor (SBDD, Structure-Based Drug Design) é uma das principais estratégias de P\&D da indústria farmacêutica moderna. A sua aplicação auxiliou a descoberta de inúmeras moléculas bioativas para uma ampla variedade de alvos moleculares. Os medicamentos para o controle do HIV/Aids representam parte vital da história de sucesso do SBDD. Além disso, outros exemplos mais recentes incluem o ivacaftor (2012, fibrose cística) (Van Goor et al., 2009), o sofosbuvir (2013, hepatite crônica) (Sofia et al., 2010), o riociguate (2013, hipertensão pulmonar) (Schermuly et al., 2008), a canagliflozina (2013, diabetes tipo 2) (Nomura et al., 2010), o erdafitinib (2019, câncer) (Murray et al., 2019), e o ripretinib (2020, câncer) (Smith et al., 2019). Um dos grandes desafios atuais é o uso de estratégias de SBDD e de planejamento de fármacos baseado na estrutura do ligante (LBDD, Ligand-Based Drug Design) para desenvolver novos medicamentos baseados no mecanismo de ação para alvos moleculares específicos do Sars-CoV-2.

O Sars-CoV-2 é formado por uma cápsula proteica, denominada capsídeo, envolvendo o material genético, o RNA, e tem em média, 120 nanômetros de tamanho. O genoma do Sars-CoV-2 foi rapidamente sequenciado e consiste em uma molécula de RNA fita simples de sentido positivo (ssRNA+) de aproximadamente $30 \mathrm{~kb}$. As fases de leitura aberta (ORF, Open Reading Frame), ORFla 
e ORFlb, que juntas compreendem mais de $21 \mathrm{~kb}$, codificam a produção de 16 proteínas não estruturais (nspl a nspl6), entre elas as enzimas indispensáveis para a replicação viral. $\mathrm{O}$ envelope esférico do vírus contém 4 proteínas estruturais: Spike (S), envelope (E), membrana $(\mathrm{M})$, e nucleocapsídeo $(\mathrm{N})$, dentro do envelope. Um terceiro grupo de 9 proteínas acessórias (3a, 3b, 6, 7a, 7b, 8, 9b, $9 c, 10)$ que não são essenciais para a replicação do vírus, mas parecem ter um papel na patogênese, completa as 29 proteínas do Sars-CoV-2 (Gordon et al., 2020; Zhou et al., 2020).

A principal protease do Sars-CoV-2 ( $\left.\mathrm{M}^{\text {pro }}\right)$ é uma cisteíno-protease essencial para a replicação viral. Ela hidrolisa ligações peptídicas em pelo menos 11 sítios conservados das poliproteínas precursoras ppla e pplab para liberar os polipeptídios precursores das proteínas funcionais. Por meio da integração da triagem virtual baseada na estrutura do receptor (SBVS, Structure-Based Virtual Screening) com a triagem biológica automatizada em alta escala (HTS, High Throughput Screening), mais de 10.000 compostos, incluindo medicamentos aprovados, candidatos em ensaios clínicos e outros compostos farmacologicamente ativos, foram avaliados contra a $\mathrm{M}^{\text {pro }}$ (Jin et al., 2020). Seis inibidores foram identificados, com valores de $\mathrm{IC}_{50}$ (concentração de inibidor para reduzir em $50 \%$ a atividade da enzima $\mathrm{M}^{\text {pro }}$ ) variando entre 0,67 e $21,4 \mu \mathrm{M}$. São eles: ebselen (inflamação), tideglusib (doença de Alzheimer), carmofur e PX-12 (câncer), shikonina (inflamação) e dissulfiram (alcoolismo) (Figura 8). No entanto, apenas o ebselen apresentou atividade in vitro contra o Sars-CoV-2.

Um outro estudo de triagem virtual, com cerca de 2.000 medicamentos aprovados, foi realizado para a identificação de inibidores da $\mathrm{M}^{\text {pro }}$ do Sars-CoV-2 (Ghahremanpour et al., 2020). Dezessete compostos foram avaliados in vitro contra a enzima-alvo e os 5 mais promissores apresentaram valores de $\mathrm{IC}_{50}$ entre 4,8 e 38,5 $\mu \mathrm{M}$. São eles: manidipina (hipertensão), boceprevir (hepatite C), lercanidipina (hipertensão), bedaquilina (tuberculose) e efonidipina (hipertensão) (Figura 9).

Outra cisteíno-protease estudada é a PL pro, uma protease relacionada à papaína. Esta enzima hidrolisa as poliproteínas precursoras ppla e pplab em três sítios de clivagem para gerar proteínas virais funcionais. Além disso, a $\mathrm{PL}^{\text {pro }}$ cliva modificações pós-traducionais em proteínas do hospedeiro e inibe as reações imunológicas mediadas por interferons, facilitando a evasão viral (Shin et al., 2020). Estudos das relações entre a estrutura e atividade (SAR, Structure-Activity Relationships) de inibidores sintéticos da PL pro revelaram o potencial de benzamidas e isoindolinas (Figura 10) contra o Sars-CoV-2 (Welker et al., 2020).

A RdRp, vital para os processos de replicação e transcrição do genoma do Sars-CoV-2, tem sido amplamente explorada para o desenvolvimento de fármacos. Ela é formada por duas subunidades acessórias (nsp7 e nsp8) e uma subunidade catalítica denominada nspl2 (Hillen et al., 2020). Alguns inibidores da RdRp são o remdesivir, favipiravir, penciclovir e ribavirina (Figura 11). 


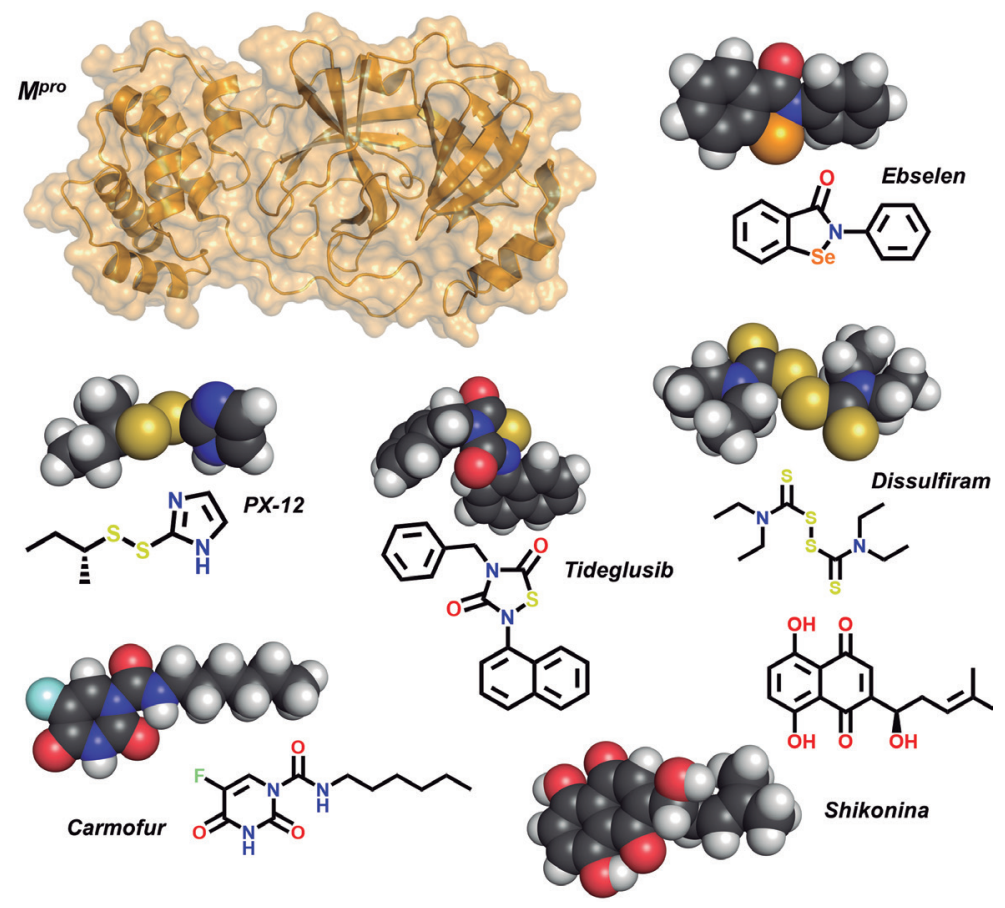

Fonte: Elaboração própria.

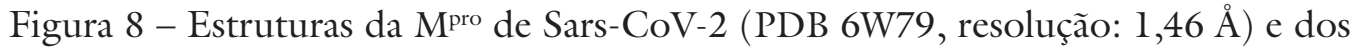
inibidores ebselen, PX-12, tideglusib, dissulfiram, carmofur e shikonina.

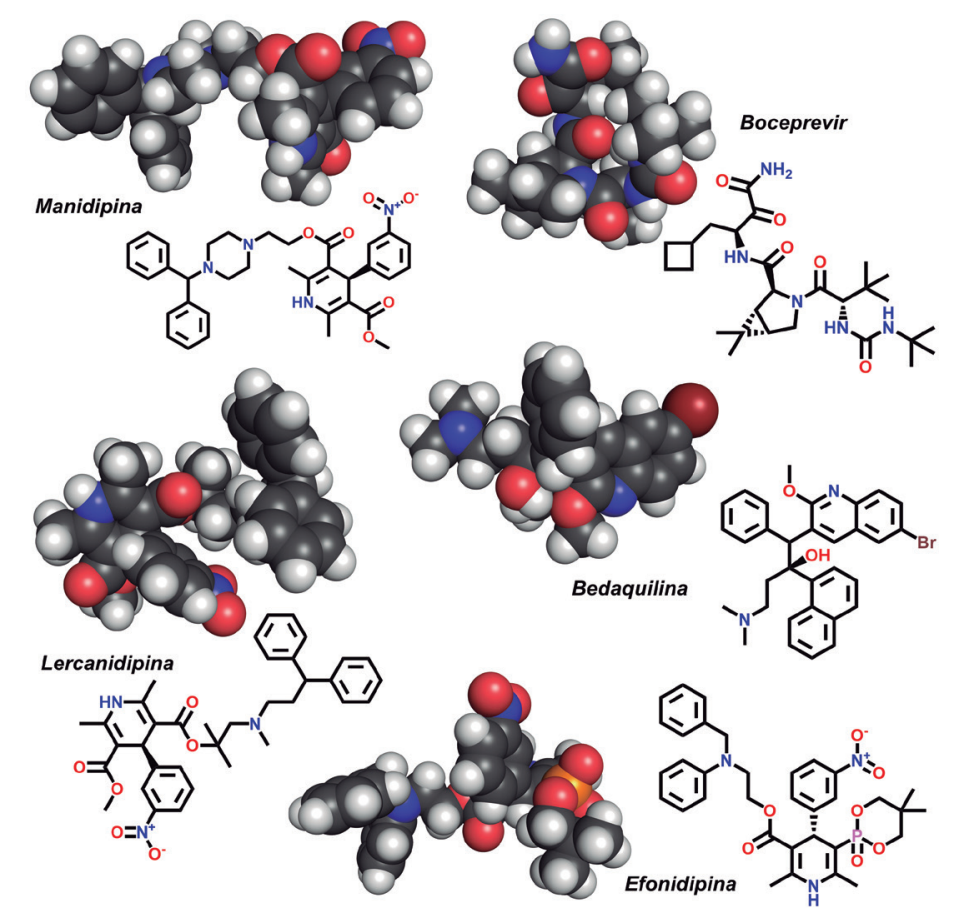

Fonte: Elaboração própria.

Figura 9 - Estruturas químicas da manidipina, boceprevir, lercanidipina, bedaquilina e efonidipina. 


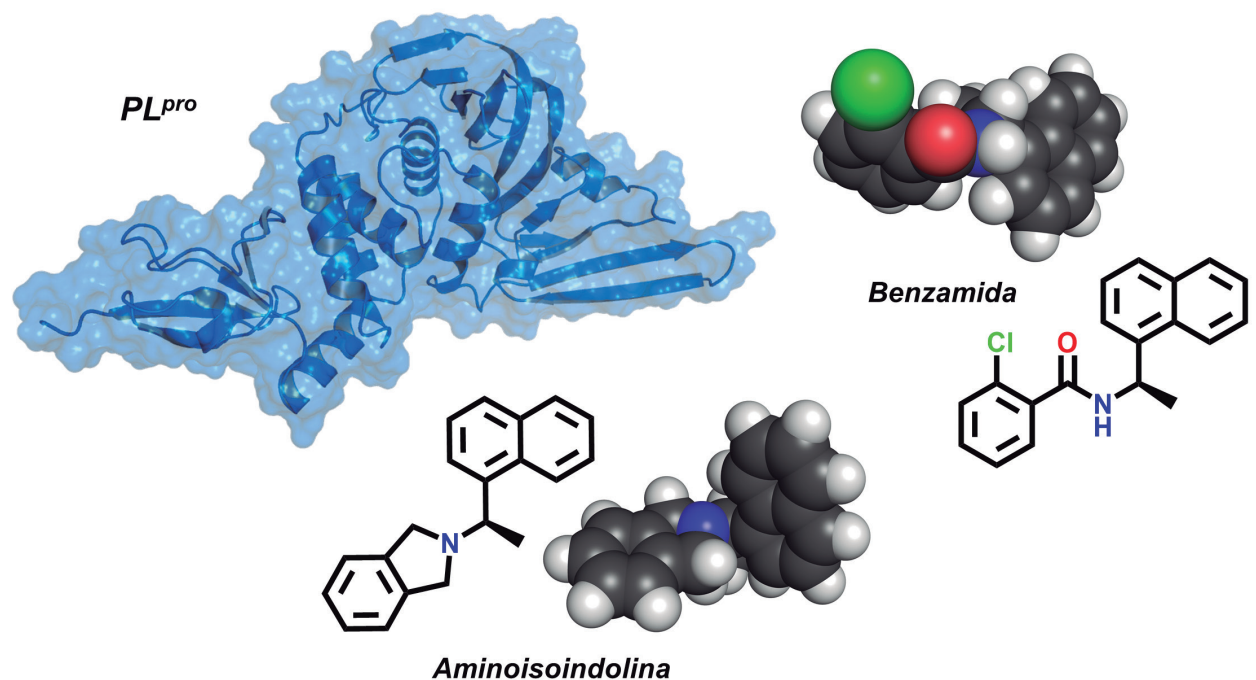

Fonte: Elaboração própria.

Figura 10 - Estruturas da PL pro de Sars-CoV-2 (PDB 7CMD, resolução: 2,59 ^̊) e dos inibidores das classes das benzamidas e isoindolinas.

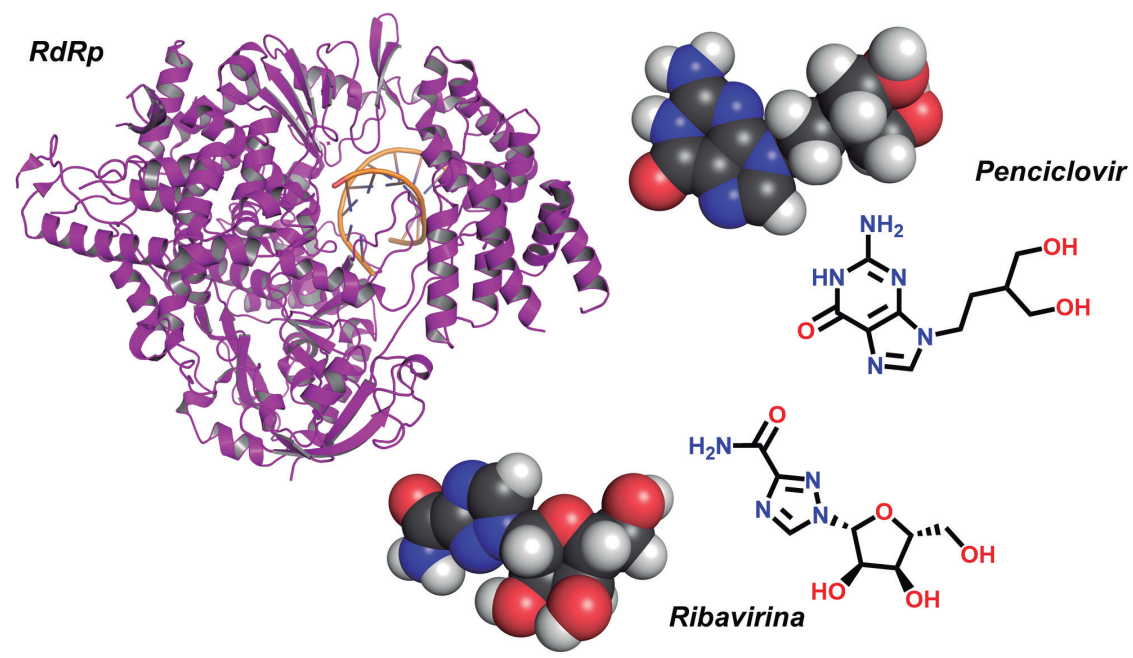

Fonte: Elaboração própria.

Figura 11 - Estruturas da RdRp de Sars-CoV-2 (PDB 6XQB, resolução: 3,40 A) e dos inibidores penciclovir e ribavirina.

A proteína estrutural S, localizada na superfície do envelope viral, é fundamental para a entrada do vírus na célula hospedeira. Formada pelas subunidades S1 e S2, ela é revestida por polissacarídeos que tem a função de camuflar o vírus e facilitar a sua evasão do sistema imunológico. A subunidade S1 se liga à ACE2 e a subunidade $S 2$ atua na fusão entre as membranas celular e viral (Figura 12) (Huang et al., 2020). O processo de ligação S-ACE2 e a subsequente fusão entre as membranas resulta na liberação do genoma viral no meio intrace- 
lular. Entre as proteínas estruturais, a proteína $S$ é o principal antígeno, sendo capaz de induzir uma resposta imune adaptativa através da produção de anticorpos específicos que conferem proteção contra o Sars-CoV-2 (Zost et al., 2020). A principal estratégia de desenvolvimento de fármacos baseada na estrutura da proteína S é o planejamento de anticorpos monoclonais. O LY-CoV555 e LY-CoV016 são anticorpos monoclonais neutralizantes que se ligam a diferentes epítopos da proteína $S$ do Sars-CoV-2 e bloqueiam a sua entrada na célula hospedeira.
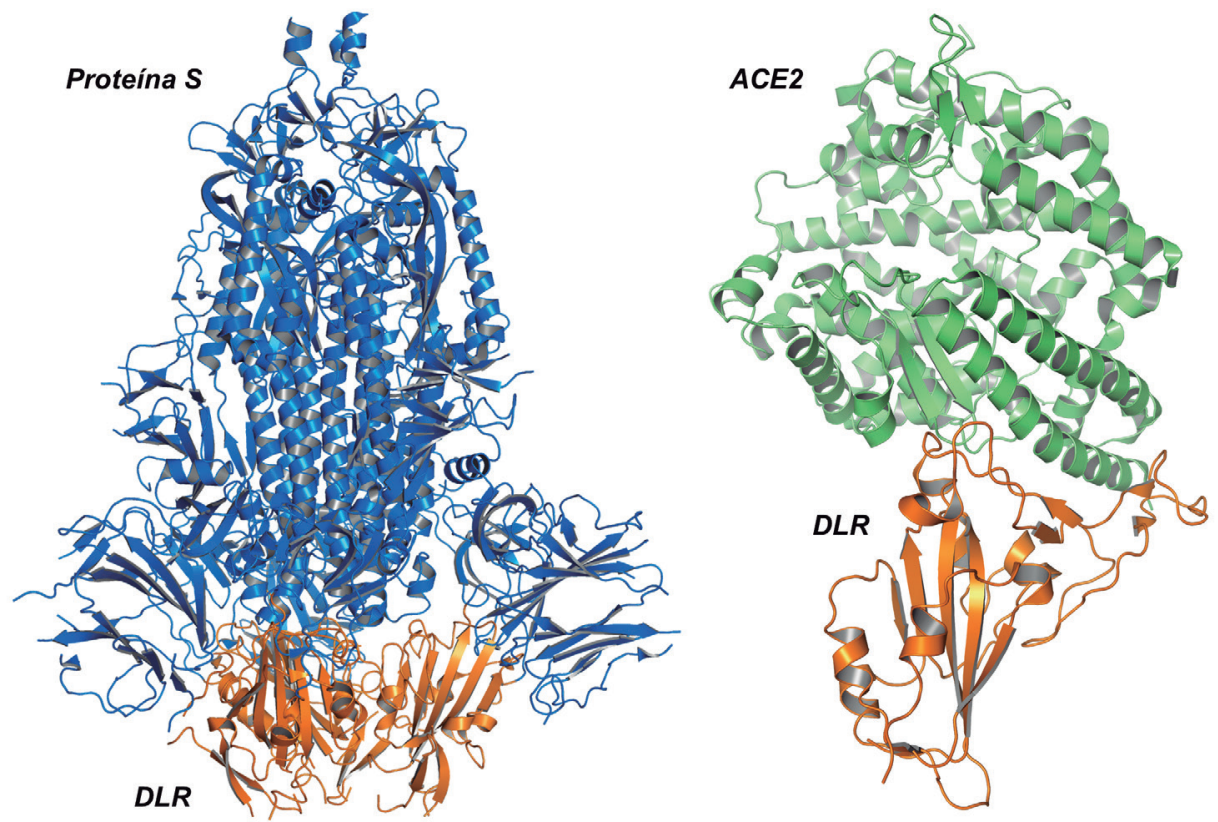

Fonte: Elaboração própria.

Figura 12 - Estrutura da proteína S de Sars-CoV-2 (PDB 6VXX, resolução: 2,80 Å) e do domínio de ligação ao receptor (DLR) em complexo com a ACE2 (PDB 6M0J, resolução: 2,45 $)$.

\section{Considerações finais}

Apesar dos extraordinários esforços da comunidade científica em todo o mundo, o desenvolvimento de novos medicamentos é um processo complexo e os resultados levam tempo para aparecer. Um longo caminho foi percorrido na busca do reposicionamento de fármacos para a Covid-19, mas nenhum novo tratamento específico foi aprovado. Após meses de testes em meio a muitas controvérsias, a realidade bateu à porta e a chance de se encontrar algum antiviral específico no espaço químico ocupado pelos fármacos aprovados é baixa ou nula. Medicamentos como a dexametasona podem ser bastante úteis individualmente para minimizar efeitos característicos da infecção, ou em conjunto, com outros coadjuvantes. No entanto, o tratamento da doença exige protagonismo e uma das principais apostas é o desenvolvimento de antivirais contra proteínas- 
-alvo do Sars-CoV-2. Esse trabalho envolve muita pesquisa multidisciplinar e o planejamento de $\mathrm{NCE}$ ou biológicos que devem passar por várias etapas pré-clínicas e clínicas. Com os alertas da OMS de que o coronavírus poderá fazer parte de nossas vidas por décadas, o desenvolvimento de antivirais específicos, com alta segurança e eficácia em humanos, é indispensável para estabelecer uma solução eficiente contra a Covid-19.

\section{Referências}

BAUM, A. et al. Antibody cocktail to Sars-CoV-2 spike protein prevents rapid mutational escape seen with individual antibodies. Science, v.369, n.6506, p.1014-18, 2020.

BIRAN, N. et al. Tocilizumab among patients with Covid-19 in the intensive care unit: a multicentre observational study. Lancet Rheumatol., 2020. No prelo. doi: 10.1016/ S2665-9913(20)30277-0. Disponível em: <https://www.thelancet.com/journals/ lanrhe/article/PIIS2665-9913(20)30277-0/fulltext>. Acesso em: 28 set. 2020.

$\mathrm{CAO}, \mathrm{B}$, et al. A trial of lopinavir-ritonavir in adults hospitalized with severe Covid-19. N. Engl. J. Med., v.382, n.19, p.1787-99, 2020.

CHEN, L. et al. Convalescent plasma as a potential therapy for Covid-19. Lancet Infect. Dis., v.20, n.4, p.398-400, 2020.

COHEN, J. Antibodies may curb pandemic before vaccines. Science, v.369, n.6505, p.752-3, 2020.

CUI, J. et al. Origin and evolution of pathogenic coronaviruses. Nat. Rev. Microbiol., v.17, n.3, p.181-92, 2019.

DE ROSSI, N. et al. Early use of low dose tocilizumab in patients with Covid-19: A retrospective cohort study with a complete follow-up. EClinicalMedicine, v.25, p.100459, 2020.

DiMASI, J. A. Research and development costs of new drugs. JAMA, v.324, n.5, p.517, 2020.

DOWDEN, H.; MUNRO J. Trends in clinical success rates and therapeutic focus. Nat. Rev. Drug Discov., v.18, n.7, p.495-6, 2019.

FERREIRA, L. G.; ANDRICOPULO, A. D. Drug repositioning approaches to parasitic diseases: a medicinal chemistry perspective. Drug Discov. Today, v.21, n.10, p.1699$1710,2016$.

FERREIRA, L. G.; ANDRICOPULO, A. D. Covid-19: Small-molecule clinical trials landscape. Curr. Top. Med. Chem., v.20, n.18, p.1577-80, 2020.

FLEXNER, C. HIV-protease inhibitors. N. Engl. J. Med., v.338, n.18, p.1281-92, 1998.

FLORINDO, H. F. et al. Immune-mediated approaches against Covid-19. Nat. Nanotechnol., v.15, n.8, p.630-45, 2020.

FUNNELL, S. G. P. et al. Emerging preclinical evidence does not support broad use of hydroxychloroquine in Covid-19 patients. Nat. Commun., v.11, n.1, p.4253, 2020.

FURLOW, B. Covacta trial raises questions about tocilizumab's benefit in Covid-19.

Lancet Rheumatol., v.2, n.10, p.e592, 2020. 
GHAHREMANPOUR, M. M. et al. Identification of 14 known drugs as inhibitors of the main protease of Sars-CoV-2. bioRxiv, 2020. Pré-print. doi: 10.1101/2020.08.28.271957. Disponível em: <https://www.biorxiv.org/content/1 0.1101/2020.08.28.271957vl>. Acesso em: 28 set. 2020.

GHOFRANI, H. A.; OSTERLOH, I. H.; GRIMMINGER F. Sildenafil: from angina to erectile dysfunction to pulmonary hypertension and beyond. Nat. Rev. Drug Discov., v.5, n.8, p.689-702, 2006.

GORDON, et al. A Sars-CoV-2 protein interaction map reveals targets for drug repurposing. Nature, v.583, n.7816, p.459-68, 2020.

HANSEN, J. et al. Studies in humanized mice and convalescent humans yield a Sars-CoV-2 antibody cocktail. Science, v.369, n.6506, p.1010-14, 2020.

HARRISON, C. Coronavirus puts drug repurposing on the fast track. Nat. Biotechnol., v.38, n.4, p.379-81, 2020.

HILLEN, H. S. et al. Structure of replicating Sars-CoV-2 polymerase. Nature, v.584, n.7819, p.154-6, 2020.

HUANG, Y. et al. Structural and functional properties of Sars-CoV-2 spike protein: potential antivirus drug development for Covid-19. Acta Pharmacol. Sin., v.41, n.9, p.1141-9, 2020.

HUNG, I. F. et al. Triple combination of interferon beta-1b, lopinavir-ritonavir, and ribavirin in the treatment of patients admitted to hospital with Covid-19: an open-label, randomised, phase 2 trial. Lancet, v.395, n.10238, p.1695-1704, 2020.

JIN, Z. et al. Structure of Mpro from Sars-CoV-2 and discovery of its inhibitors. Nature, v.582, n.7811, p.289-93, 2020.

JOMAH, S.; ASDAQ, S. M. B.; AL-YAMANI, M. J. Clinical efficacy of antivirals against novel coronavirus (Covid-19): A review. J. Infect. Public Health., v.13, n.9, p.1187-95, 2020.

KEWAN, T. et al. Tocilizumab for treatment of patients with severe Covid-19: A retrospective cohort study. EClinicalMedicine, v.24, p.100418, 2020.

KISHIMOTO, T. K. et al. Improving the efficacy and safety of biologic drugs with tolerogenic nanoparticles. Nat. Nanotechnol., v.11, n.10, p.890-9, 2016.

KUPFERSCHMIDT, K.; COHEN, J. Race to find Covid-19 treatments accelerates. Science, v.367, n.6485, p.1412-1413, 2020.

LEDFORD, H. Evidence lags behind excitement over blood plasma as a coronavirus treatment. Nature, v.584, n.7822, p.505, 2020.

LIU, J. et al. Hydroxychloroquine, a less toxic derivative of chloroquine, is effective in inhibiting Sars-CoV-2 infection in vitro. Cell Discov., v.6, n.16, 2020.

MAISONNASSE, P. et al. Hydroxychloroquine use against Sars-CoV-2 infection in non-human primates. Nature, v.585, n.7826, p.584-587, 2020.

MONTEIL, V. et al. Inhibition of Sars-CoV-2 infections in engineered human tissues using clinical-grade soluble human ACE2. Cell, v.181, n.4, p.905-13.e7, 2020.

MURRAY, C. W. et al. A successful collaboration between academia, biotech and pharma led to discovery of erdafitinib, a selective FGFR inhibitor recently approved by the FDA. MedChemComm, v.10, n.9, p.1509-11, 2019. 
NATIONAL INSTITUTES OF HEATH (NIH). Disponível em: <NIH ACTIV initiative launches adaptive clinical trials of blood-clotting treatments for COVID-19>. Acesso em: 28 set. 2020.

NOMURA, S. et al. Discovery of canagliflozin, a novel C-glucoside with thiophene ring, as sodium-dependent glucose cotransporter 2 inhibitor for the treatment of type 2 diabetes mellitus. J. Med. Chem., v.53, n.17, p.6355-60, 2010.

NORMAND, S. T. The RECOVERY platform. N. Engl. J. Med., 2020. doi:10.1056/ NEJMe2025674. Disponível em: <https://www.nejm.org/doi/full/10.1056/NEJMe2025674>. Acesso em: 28 set. 2020.

PACKARD, R. M. The origins of antimalarial-drug resistance. N. Engl. J. Med., v.371 n.5, p.397-9, 2014.

PUSHPAKOM, S. et al. Drug repurposing: progress, challenges and recommendations. Nat. Rev. Drug Discov., v.18, n.1, p.41-58, 2019.

RECOVERY Collaborative Group et al. Dexamethasone in hospitalized patients with Covid-19 - preliminary report. N. Engl. J. Med., 2020. doi: 10.1056/NEJMoa2021436. Disponível em: <https://www.nejm.org/doi/10.1056/NEJMoa2021436>. Acesso em: 28 set. 2020).

ROSENBERG, E. S. et al. Association of treatment with hydroxychloroquine or azithromycin with in-hospital mortality in patients with Covid-19 in New York State. $J A M A$, v.323, n.24, p.2493-502, 2020.

SCHERMULY, R.T. et al. Expression and function of soluble guanylate cyclase in pulmonary arterial hypertension. Eur. Respir. J., v.32, n.4, p.881-91, 2008.

SHEAHAN, T. P. et al. Broad-spectrum antiviral GS-5734 inhibits both epidemic and zoonotic coronaviruses. Sci. Transl. Med., v.9, n.396, p.eaal3653, 2017.

SHIN, D. et al. Papain-like protease regulates Sars-CoV-2 viral spread and innate immunity. Nature, 2020. doi: 10.1038/s41586-020-2601-5. Disponível em: <https:// www.nature.com/articles/s41586-020-2601-5>. Acesso em: 28 set. 2020.

SMITH, B. D. et al. Ripretinib (DCC-2618) is a switch control kinase inhibitor of a broad spectrum of oncogenic and drug-resistant KIT and PDGFRA variants. Cancer Cell, v.35, n.5, p.738-51.e9, 2019.

SOFIA, M. J. et al. Discovery of a -d-2'-deoxy-2'- -fluoro-2'- -C-methyluridine nucleotide prodrug (PSI-7977) for the treatment of hepatitis C virus. J. Med. Chem., v.53, n.19, p.7202-18, 2010.

TANDON, R. et al. Effective Inhibition of Sars-CoV-2 entry by heparin and enoxaparin derivatives. bioRxiv, 2020. Pré-print. doi: 10.1101/2020.06.08.140236. Disponível em: <https://www.biorxiv.org/content/10.1101/2020.06.08.140236vl>. Acesso em: 28 set. 2020.

THE LANCET INFECTIOUS DISEASES. Curing Covid-19. Lancet Infect. Dis., 2020. doi: 10.1016/S1473-3099(20)30706-4. Disponível em: <https://www.thelancet.com/journals/laninf/article/PIIS1473-3099(20)30706-4/fulltext>. Acesso em: 28 set. 2020 .

TU, X. et al. Structural basis of HIV-1 resistance to AZT by excision. Nat. Struct. Mol. Biol., v.17, n.10, p.1202-1209, 2010. 
VAN GOOR, F. et al. Rescue of CF airway epithelial cell function in vitro by a CFTR potentiator, VX-770. Proc. Natl. Acad .Sci. U. S. A., v.106, n.44, p.18825-30, 2009.

WARREN, T. K. et al. Therapeutic efficacy of the small molecule GS-5734 against Ebola virus in rhesus monkeys. Nature, v.531, n.7594, 381-385, 2016.

WELKER, A. et al. SAR of novel benzamides and isoindolines, designed as SARS-CoV protease inhibitors - effective against Sars-CoV-2. ChemMedChem, 2020. doi:10.1002/ cmdc.202000548. Disponível em: <https://chemistry-europe.onlinelibrary.wiley. com/doi/10.1002/cmdc.202000548>. Acesso em: 28 set. 2020.

WERMUTH, C. G. et al. Glossary of terms used in medicinal chemistry (IUPAC Recommendations 1998). Pure Appl. Chem., v.70, n.5, p.1129-1143, 1998.

WORLD HEALTH ORGANIZATION (WHO). Coronavirus disease (Covid-19) pandemic. Disponível em: <https://www.who.int/emergencies/diseases/novel-coronavirus-2019>. Acesso em: 27 set. 2020.

WORLD HEALTH ORGANIZATION (WHO). WHO Coronavirus Disease (Covid-19) Dashboard. Disponível em: <https://covid19.who.int/>. Acesso em: 27 set. 2020.

ZAKI, A. M. et al. Isolation of a novel coronavirus from a man with pneumonia in Saudi Arabia. N. Engl. J. Med., v.367, n.19, p.1814-20, 2012.

ZELIKIN, A. N.; EHRHARDT, C.; HEALY, A. M. Materials and methods for delivery of biological drugs. Nat. Chem., v.8, n.11, p.997-1007, 2016.

ZHONG, N. S. et al. Epidemiology and cause of severe acute respiratory syndrome (SARS) in Guangdong, People's Republic of China, in February, 2003. Lancet, v.362, n.9393, p.1353-1358, 2003.

ZHOU, Y. et al. Network-based drug repurposing for novel coronavirus 2019-nCoV/ Sars-CoV-2. Cell Discov., v.6, n.1, p.1-18, 2020.

ZHU, N. et al. A Novel Coronavirus from patients with pneumonia in China, 2019. N. Engl.J. Med., v.382, n.8, p.727-33, 2020.

ZOST, S. J. et al. Potently neutralizing and protective human antibodies against Sars-CoV-2. Nature, v.584, n.7821, p.443-9, 2020.

RESUMO - Existem no mundo cerca de 2.000 registros de ensaios clínicos para a investigação de medicamentos aprovados e outros candidatos para a Covid-19, incluindo moléculas pequenas e medicamentos biológicos, sem contar as vacinas. O reposicionamento de fármacos, estratégia mais explorada até o momento, não levou a qualquer novo tratamento antiviral contra a Covid-19. O remdesivir, apesar de sua aprovação emergencial pela agência reguladora norte-americana, apresentou somente resultados modestos em estudos clínicos. A dexametasona, que contribuiu para reduzir a mortalidade em pacientes graves recebendo ventilação mecânica invasiva ou oxigênio, é um corticoide que possui propriedades anti-inflamatórias e imunossupressoras. Os medicamentos biológicos, por sua vez, como anticorpos monoclonais, interferons, proteínas específicas e anticoagulantes estão sendo avaliados em diversas triagens clínicas para definir o seu papel na terapia da doença. A Organização Mundial da Saúde (OMS) alertou que o 
coronavírus poderá nunca desaparecer, mesmo com uma eventual vacina, evidenciando a urgência de pesquisas por novos fármacos inovadores. O cenário atual mais realista compreende o desenvolvimento de antivirais específicos contra o Sars-CoV-2 para o tratamento seguro e eficaz da doença.

PALAVRAS-CHAVE: Covid-19, Ensaios clínicos, Medicamentos, Química medicinal, Reposicionamento de fármacos, Alvo molecular, Sars-CoV-2.

ABSTRACT - Approximately 2,000 clinical studies have been conducted in the world to investigate approved drugs and drug candidates for Covid-19, including small molecules and biologicals, not to mention vaccines. The repositioning of drugs, the most explored strategy, has not led to the identification of any new antiviral against Covid-19. Despite its approval for emergency use by the US regulatory agency, remdesivir has shown only modest results in clinical studies. Dexamethasone, which contributed to reduce mortality in critically ill patients receiving mechanical ventilation or oxygen, is a corticosteroid that has anti-inflammatory and immunosuppressive properties. Biological drugs, such as monoclonal antibodies, interferons, specific proteins, and anticoagulants are being evaluated in several clinical studies to assess their role in Covid-19 therapy. The World Health Organization (WHO) has warned that the coronavirus may never disappear even with the advent of an eventual vaccine, highlighting the urgency for the development of innovative drugs. The most realistic scenario involves the development of specific antivirals against Sars-CoV-2 for the safe and effective treatment of the disease.

KErWords: Covid-19, Clinical studies, Drugs, Medicinal chemistry, Drug repositioning, Molecular target, Sars-CoV-2.

Leonardo L. G. Ferreira é pesquisador do Instituto de Física de São Carlos (IFSC) da USP e do Centro de Pesquisa e Inovação em Biodiversidade e Fármacos (CIBFar), um dos Centros de Pesquisa, Inovação e Difusão (Cepid) financiados pela Fapesp. @ - leonardo@ifsc.usp.br / https://orcid.org/0000-0002-6947-0639.

Adriano D. Andricopulo é professor titular do Instituto de Física de São Carlos (IFSC) da USP, coordenador de Transferência de Tecnologia do Centro de Pesquisa e Inovação em Biodiversidade e Fármacos (CIBFar), um dos Centros de Pesquisa, Inovação e Difusão (Cepid) financiados pela Fapesp, e diretor executivo da Academia de Ciências do Estado de São Paulo (Aciesp). @ - aandrico@ifsc.usp.br /

https://orcid.org/0000-0002-0457-818X.

Recebido em 29.9.2020 e aceito em 5.10.2020.

I, II Instituto de Física de São Carlos, Universidade de São Paulo, São Carlos, São Paulo, Brasil. 
